\title{
Syringocystadenoma Papilliferum of External Auditory Canal: A Rare Entity
}

\author{
${ }^{1}$ Sunil Kumar, ${ }^{2}$ Hitendra P Singh, ${ }^{3}$ Ajay K Singh
}

\begin{abstract}
Syringocystadenoma papilliferum is a benign adnexal tumor that frequently shows apocrine differentiation. It has propensity to develop in the scalp region. It is a rare tumor and usually appears at birth or during puberty, hence, it is also called childhood tumor. Although it may differ in clinical presentation, its histology is characteristic. In this study, we have described the syringocystadenoma papilliferum in the external auditory canal of a 45-year-old female because of its occurrence in an unusual site and in an uncommon age.
\end{abstract}

Keywords: Childhood tumor, External auditory canal, Syringocystadenoma papilliferum.

How to cite this article: Kumar S, Singh HP, Singh AK. Syringocystadenoma Papilliferum of External Auditory Canal: A Rare Entity. Int J Head Neck Surg 2016;7(4):223-224.

\section{Source of support: Nil}

Conflict of interest: None

\section{INTRODUCTION}

Syringocystadenoma papilliferum is a rare benign adnexal tumor of the apocrine or the eccrine type with characteristic histological findings. It is called childhood tumor, as it usually appears at birth or during puberty. In about 50\% of cases it is present at birth, and in 15 to $30 \%$ cases the tumor develops before puberty. ${ }^{1}$ This tumor commonly occurs on the head and neck and rarely found on eyelids, trunk, ${ }^{2}$ genitelia, ${ }^{3}$ and lower extremities. Lesions on the face and neck region are usually of linear type, and the solitary nodular type shows predilection for the trunk. ${ }^{4}$

\section{CASE REPORT}

A 45-year-old female presented to us in the outpatient department with the chief complaint of pain and discharge from right ear for 6 months. Pain was mild in

\footnotetext{
${ }^{1-3}$ Associate Professor

${ }^{1,2}$ Department of ENT and Head and Neck Surgery, King George's Medical University, Lucknow, Uttar Pradesh, India

${ }^{3}$ Department of Pathology, King George's Medical University Lucknow, Uttar Pradesh, India

Corresponding Author: Sunil Kumar, Associate Professor Department of ENT and Head and Neck Surgery, King George's Medical University, Lucknow, Uttar Pradesh, India, Phone: +919415820661, e-mail: drsunil_kumar123@rediffmail.com
}

severity and not radiating to surrounding area. Discharge was serous, scanty, and nonfoul smelling. There was no history of vertigo or hearing loss. Patient was not a known case of diabetes and hypertension. On examination, a small mass was present in the external auditory canal arising from its posterior wall (Fig. 1). Endoscopic examination revealed that the tympanic membrane was normal. Routine hematological investigation was normal. After proper consent, mass was completely excised under local anesthesia with normal postoperative recovery. On microscopic examination, section was lined by keratinized stratified squamous epithelium with underlying epithelial proliferation in the form of tubules, cysts, papillae with fibrovascular cores and lined by luminal columnar cells with oval bland nuclei and abluminal myoepithelial cells. Few cells showed apocrine differentiation with eosinophilic cytoplasm and prominent snouting at places. Intervening collagenous stroma is infiltrated with chronic inflammatory cells (Figs 2 and 3). Lesion was diagnosed histopathologically as syringocystadenoma papilliferum.

\section{DISCUSSION}

Syringocystadenoma papilliferum is a benign adnexal skin tumor of the apocrine or the eccrine type with characteristic histological features and varied and nondistinct clinical findings. Clinically, most of the cases are first seen at birth. Other cases develop in infancy, childhood, and adolescence, but in our case, it was present at 45 years of

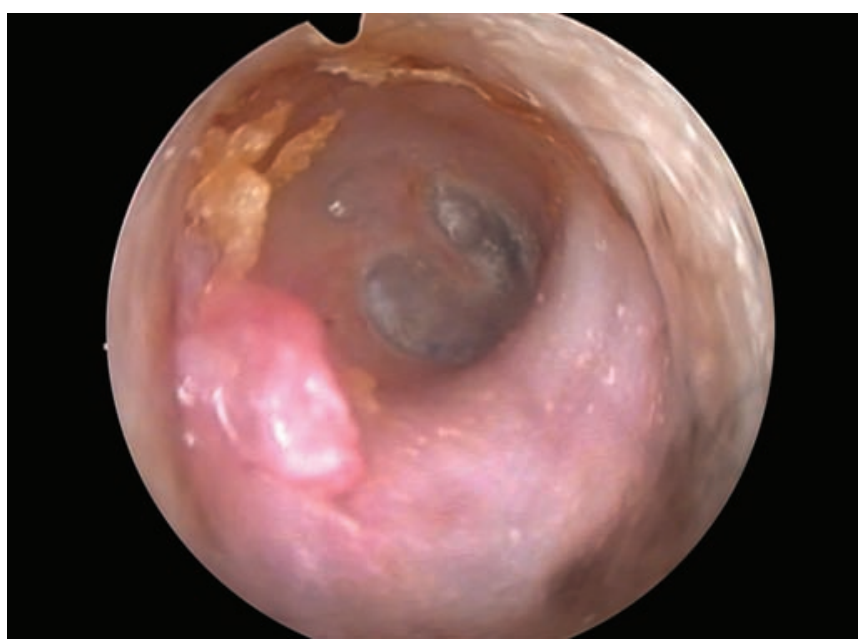

Fig. 1: Small mass over posterior wall of external auditory canal with normal tympanic membrane 


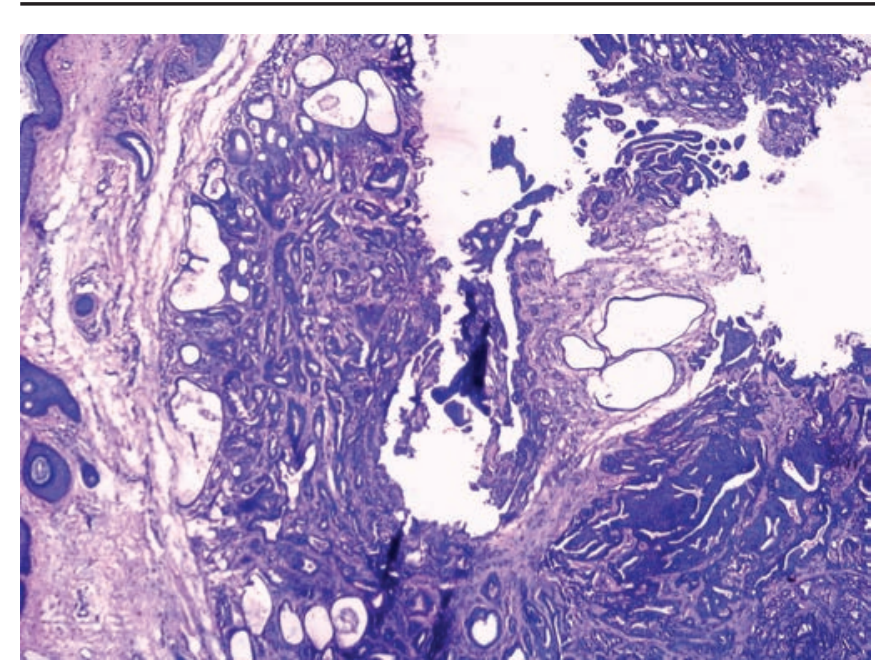

Fig. 2: Exhibit of a cystic invagination into the dermis, with numerous papillary projection and many cystic areas along with groups of tubular glands (hematoxylin and eosin, 10x)

age. The tumor presents either as one papule or several papules in a linear arrangement, or as a solitary plaque. The nodular type of lesions has its predilection for the trunk, but in our case, it was present in the external auditory canal. It is commonly associated with hamartomatous lesion of follicular or sebaceous origin and sebaceous nevus. Other tumors, such as trichilemmoma, apocrine adenomas, hidradenoma papilliferum, trichoblastomas, may also arise from the sebaceous nevus. ${ }^{5}$ Syringocystadenocarcinoma papilliferum and few cases of verrucous and ductal carcinomas are reported to arise from syringocystadenoma papilliferum. ${ }^{6,7}$ Rapid enlargement and ulceration of the lesion is indicative of a malignant transformation. As there is risk of malignant transformation, a prophylactic surgical excision with detailed histopathological examination is the mainstay of treatment. Considering the size and the ulceration of the lesion, complete excision was done, which after histopathological examination was proved to be benign, and a malignant transformation of the tumor was not seen. There were no signs of recurrence even after a follow-up period of 1 year.

\section{CONCLUSION}

Syringocystadenoma papilliferum is a rare benign tumor. Though it usually appears at birth, it can be present in

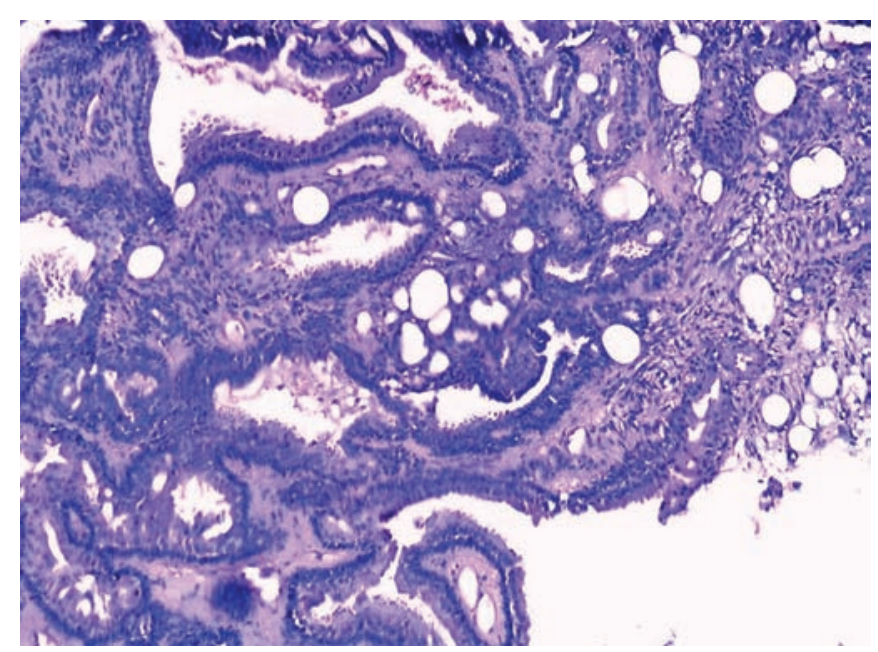

Fig. 3: Papillary projection lined by two row of cells, the luminal row of cells consist of columnar cells with evidence of active decapitation secretion (hematoxylin and eosin, 40x)

adults too. The nodular variety has a predilection for the trunk, but here, it presented on the external auditory canal. As there is potential of malignant transformation, it should undergo complete surgical excision and histopathological examination.

\section{REFERENCES}

1. Karg E, Korom I, Varga E, Ban G, Turi S. Congenital syringocystadenoma papilliferum. Pediatr Dermatol 2008 Jan-Feb;25(1):132-133.

2. Epstein BA, Argenyi ZB, Goldstein G, Whitaker D. An unusual presentation of a congenital benign apocrine hamartoma. J Cutan Pathol 1990 Feb;17(1):53-58.

3. Coyne JD, Fitzgibbon JF. Mixed syringocystadenoma papilliferum and papillary eccrine adenoma occurring in a scrotal condyloma. J Cutan Pathol 2000 Apr;27(4):199-201.

4. Katoulis AC, Bozi E. Syringocystadenoma papilliferum. Orphanet Encyclopedia 2004;1:1-3.

5. Stavrianeas NG, Katoulis AC, Stratigeas NP, Karagianni IN, Patertou-Stavrianea M, Varelzidis AG. Development of multiple tumors in a sebaceous nevus of Jadassohn. Dermatology 1997;195(2):155-158.

6. Monticciolo NL, Schmidt JD, Morgan MB. Verrucous carcinoma arising within syringocystadenoma papilliferum. Ann Clin Lab Sci 2002 Fall;32(4):434-437.

7. Hügel H, Requena L. Ductal carcinoma arising from a syringocystadenoma papilliferum in a nevus sebaceous of Jadassohn. Am J Dermatopathol 2003 Dec;25(6):490-493. 